\title{
PROGRESS WITH AIR QUALITY MANAGEMENT IN THE 60 YEARS SINCE THE UK CLEAN AIR ACT, 1956. LESSONS, FAILURES, CHALLENGES AND OPPORTUNITIES.
}

\author{
J.W.S. LONGHURST, J.H. BARNES, T.J. CHATTERTON, E.T. HAYES \& W.B. WILLIAMS \\ Air Quality Management Resource Centre, University of the West of England, Bristol, England
}

\begin{abstract}
This paper explores the challenges, opportunities and progress made with managing air quality since the United Kingdom parliament passed the Clean Air Act, 1956. It seeks to identify the factors contributing to successful management of air quality and the factors that have acted, or continue to do so, as barriers to progress. The public health catastrophe of the 1952 London Smog created the political momentum for the 1956 Act to be passed. The nature of the contemporary air pollution challenge is reviewed in terms of the public health burden, the economic cost and the governmental response. The contemporary response is considered inadequate for the scale and intensity of the problem.

Keywords: air pollution, air quality management, public health, policy, regulation.
\end{abstract}

\section{INTRODUCTION}

The year 2016 marks 60 years since the United Kingdom parliament passed the 1956 Clean Air Act. This paper explores the lessons, challenges, opportunities and progress since the Act became law. It reflects upon the attempts to improve the management of air pollution at the local, national and European scale over the 60 years since the Clean Air Act. The activity stimulated by the Act helped the UK to achieve a leading position in the battle against air pollution. The challenge confronting policy makers in the early 1950s was significant but made a little easier by the overwhelming importance of a single fuel, coal and essentially two pollutants of concern, smoke and $\mathrm{SO}_{2}$. The situation today is much more complicated with multiple fuel sources and a range of pollutants. This paper focuses upon $\mathrm{NO}_{2}$ and particulate matter (PM) as pollutants of significant contemporary UK concern from the perspective of public health. Today, the UK cannot be said to have a leading position in the fight against air pollution. The nature of the contemporary UK air pollution climate and the limited and likely ineffectual policy response does not provide evidence to support a leadership claim. The scale of the air pollution challenge is substantially greater than the position 60 years ago, and the policy response is weak, uncoordinated, under resourced and lacking political will and agency to address the public health impacts of contemporary air pollution.

\section{REFLECTING ON THE 1952 SMOG AND THE 1956 CLEAN AIR ACT}

In 1952, London experienced a major smog event which led to large numbers of excess deaths and substantial increases in respiratory illness [1,2]. This public health toll was the most significant amongst the many reported smog events in London's history that stretch 
back over many centuries. Its impacts on health were profound and such was the public response to the problem that political action to ensure it could not be repeated was inevitable.

On Friday December 5th 1952, an unusually severe fog descended upon London as a slow moving anticyclone came to a halt over the city. On Friday morning, the fog was the thickest in living memory. It grew thicker throughout the day and people began to experience discomfort in breathing. Those outside rapidly became smoke blackened and aware of the choking smell. That evening respiratory cases, especially bronchitis, were twice the normal rate. Some million chimneys added more smoke to the fog [1,2]. On Saturday, visibility was near zero, prize animals at Smithfield showed illness and some had been destroyed. At Sadler's Wells, an opera performance had to be stopped due to poor visibility in the theatre. People continued to suffer health effects. On December 8th, the fog was as thick as ever and respiratory problems continued to be reported. Transportation was at a complete standstill. The fog finally cleared on the 10th of December as the anticyclone moved away.

It is estimated that 4000 excess deaths were caused by the 1952 London smog $[1,2]$. The number of deaths has subsequently been a subject of some debate with 12,000 excess deaths and some 100,000 cases of respiratory illness being suggested. Recent work by Hansell et al. [3] suggests that exposure to high air pollution concentrations carries a long-term risk to health. The smog of 1952 was a catastrophe with a very high increase in respiratory mortality and morbidity. As is often the case in environmental matters, it was the acute impact that was the catalyst for legislation. It is interesting to ask why a catastrophe was necessary for action to be taken. The sources, impacts and controls were well known before the $1952 \mathrm{smog}$, indeed had in part been known since the 17th Century. Complexity, cost and indifference may explain why action was not taken, and it is clear that mitigating the public health impact was not afforded a sufficiently high priority. What is often overlooked is that prolonged exposure to high winter time concentrations of smoke reduced the quality of life, causing illness for many and brought an early death to many more [1]. The total of deaths foreshortened through the winter time smogs far outweighs the deaths caused by the $1952 \mathrm{smog}$, but they were not enough to bring the effective change. That required a catastrophe.

In 1953, the Beaver Committee was established to 'examine the nature, causes and effects of air pollution and the efficacy of present preventative measures; to consider what further measures are practicable; and to make recommendations for action by the government' [2]. The Beaver Committee estimated the cost of air pollution in 1954 as $£ 250$ million and recommended the clearance of obsolete laws and administrative practices and the creation of a policy framework for clean air, an act to cover domestic and industrial emissions of smoke from new and existing premises [4]. The Clean Air Act, 1956 was a direct response to public outrage at the catastrophic smog of 1952. It banned dark smoke emissions from chimneys, railway engines and vessels, required new furnaces to be smokeless, required the emissions of grit and dust from furnaces to be minimised, and gave local councils' powers to introduce smokeless zones.

The Clean Air Acts dealt with visible pollution especially smoke [5]. They had a dramatic effect in reducing the concentration of visible black smoke particles in the air. The emphasis on visible pollutants was appropriate at the time the Act came into statute. The success was due to the focus on one fuel - coal - and on the emission of black smoke [5]. Their success bred complacency and fostered a view that urban air pollution had been conquered. Black smoke had been dealt with, but the problem of gaseous pollutants and fine particles would return later as the location of sources, the intensity of the sources of emission and changes in 
the composition of air pollution [5]. Concentrations of pollutants regulated by the 1956 Act and successor statutes fell whilst those from motor vehicles increased substantially in the period from 1985 onwards [5].

The Clean Air Act demonstrated that substantial air quality improvements could be produced when concerted and sustained governmental action was directed at an environmental and public health problem [2,6]. However, the importance of sustained interest became apparent later on as elimination of 'pea soupers' created a prevailing ideology that air pollution had been conquered. Resources were directed towards other problems as governmental interest, and the onset of health-based concerns about the impacts of the growth of road traffic in the 1980s and 1990s left the UK woefully ill prepared to tackle a new form of air pollution [5]. As a result of growing public health concerns related to asthma and children, the Environment Act of 1995 and the first National Air Quality Strategy in 1997 laid the foundations for what promised to be a sustained and concerted attempt to not only manage air pollution but also reduce it below risk levels for the public health [5]. However, the political support for the radical actions required to manage the sources of air pollution contributing to today's $\mathrm{NO}_{2}$ and $\mathrm{PM}$ public health challenges appears absent with policy proposals and interventions today failing to recognise the scale and intensity of the public health challenge posed by air pollution $[7,8]$.

\section{THE POLICY AND REGULATORY CONTEXT TODAY}

The governmental responsibility for air quality is shared within the UK. The lead government department is the Department for Environment, Food and Rural Affairs with responsibilities for international air quality matters, reporting to the EU, overseeing the operation of the Air Quality Strategy and for the Local Air Quality Management (LAQM) process. Air quality is a shared responsibility with the devolved administrations in Scotland, Wales and Northern Ireland also having responsibilities for air quality and its management. Local authorities are responsible for implementing LAQM and for reporting to Defra or the relevant devolved administration. In London, the Mayor has devolved powers to improve air quality in the capital.

The 1997 National Air Quality Strategy [9], legislated by the 1995 Environment Act [10], provided a consistent UK approach to air quality management, committed to ensuring access for all citizens to outdoor air without significant health risk [9]. The Strategy identified national measures to tackle larger scale issues such as vehicle fuel quality, engine technology standards and emissions from combustion processes whilst local air quality management became the remit of Local Governments recognising the importance of subsidiarity, and the need for proportionate, collaborative action that takes account of the local context. The Strategy set out the means to manage air quality and to protect health from the effects of air pollution through national and local-level action to comply with Air Quality Objectives (AQOs) for selected air pollutants: benzene, 1,3-butadiene, carbon monoxide, lead, nitrogen dioxide, ozone, particulate matter (PM10) and sulphur dioxide [11]. Air Quality Objectives specified in the UK Air Quality Regulations [12] were set at levels below which effects are unlikely (even in sensitive groups) or the risk of an effect is exceedingly small.

Since 1997, relevant European Air Quality Directives have been consolidated as the European Ambient Air Quality Directive 2008/50/EC and three revisions of the UK National Air Quality Strategy have been published. The Air Quality Strategy, 2000 recognised that 'Clean air is an essential ingredient of a good quality of life. People have the right to expect that the air they breathe will not harm them' [13]. The most recent Air Quality Strategy for England, 
Scotland, Wales and Northern Ireland was published in 2007 [14] whilst the last update to the UK Air Quality Regulations was published in 2010 [15]. Clearly these policy and regulatory positions require updating but there appears little appetite in government to do so.

Despite some process-reporting streamlining and modifications of AQO timescales, values and/or exceedence limits, LAQM's two-stage effects-based approach of air quality assessment in the context of public exposure followed, where necessary, by an AQMA declaration and development of an action plan, has remained largely unchanged since its inception $[8,11$, $16,17]$.

\section{EUROPEAN LIMIT VALUES}

Despite improvements in the quantity of emissions of many pollutants, such as smoke and sulphur dioxide, particularly from industrial and domestic sources, profound problems of air pollution continue to exist especially at the local level. Pollutants whose origins are in emissions from traffic remain the cause of many instances of exceedances of standards and guidelines. The EEA's 2015 analysis on air quality in Europe reports that air quality policies have delivered many improvements, including reductions in emissions and for some pollutants few exceedences of European standards now occur [18]. However, substantial challenges remain for some pollutants with significant impacts on human health and the environment reported [18]. The EAA identifies a large proportion of the European population and ecosystems as still exposed to selected air pollutants in exceedance of European standards and WHO Air Quality Guidelines [18].

The EEA notes that effective air quality policies require action and cooperation on global, European, national and local scales which must address all economic sectors and engage the public. Holistic solutions are required involving technological developments, structural changes, infrastructure optimisation, urban planning and behavioural changes. In 2013, the EU limit and target values for PM were exceeded in large parts of Europe whilst the annual limit value for $\mathrm{NO}_{2}$ was widely exceeded across Europe particularly in locations close to roads [18]. The EEA reports that in $201317 \%$ of the EU population was exposed to $\mathrm{PM}_{10}$ concentrations above the daily limit value, whilst $61 \%$ were exposed to concentrations exceeding the WHO daily guideline for $\mathrm{PM}_{10}$ [18]. In the case of $\mathrm{NO}_{2}, 9 \%$ of the EU population live in areas which exceed the annual EU limit value and the WHO annual guideline. The EEA estimates that 403,000 premature deaths in the EU are due to long term expose to $\mathrm{PM}_{2.5}$ and a further 72,000 premature deaths in the $\mathrm{EU}$ are due to long-term exposure to $\mathrm{NO}_{2}[18]$.

\section{THE UK POSITION}

The UK government has the responsibility to report to the European Commission on compliance with European Limit Values within the UK space. In 2013, the UK exceeded the EU limit value for $\mathrm{NO}_{2}$ annual mean at 31 of its 43 zones and agglomerations (38 excluding the Margin of Tolerance). Current government predictions are that full compliance will not be achieved until 2025. In April 2015, following a legal challenge by ClientEarth, the Supreme Court ruled that the UK is in breach of the European Air Quality Directive, and insisted that the government draw up a plan for compliance by the end of this year. In 2015, the UK Government consulted on its proposals and in late 2015 published its plan to comply with the European Air Quality Directive.

In the UK, air quality exceedances are most clearly evidenced by the declaration of Air Quality Management Areas (AQMAs) in 250 (62\%) of the UK's Local Authorities [11]. The overwhelming cause of the air quality problem is the emissions from road traffic. The scale 
of individual AQMAs varies from the very small discrete areas covering a relatively small number of houses to those that cover the entire administrative area of a local authority. However, they all share one characteristic and that is that the population is exposed to a concentration that exceeds a value determined by government at which action should be taken to delineate the problem and to reduce the concentration. In nearly every AQMA, the cause of the declaration is nitrogen dioxide, in a small number of cases the problem is $\mathrm{PM}_{10}$. The health impacts will vary considerably between AQMAs due to the differences in air pollution exposures but also will vary due to differences in individual and population-level susceptibilities [11].

Local authority air quality management action is divided into two part Review and Assessment and Action Planning [17, 19, 20]. Review and Assessment is a phased risk-management approach to review air quality in locations where the public is likely to be regularly present. Where an AQO is exceeded and relevant public exposure is present an Air Quality Management Area (AQMA) declaration is required. Following an AQMA declaration, a local authority must develop and implement an Air Quality Action Plan (AQAP) designed to bring air quality in the AQMA back within acceptable limits. The process of LAQM generates repeatable and efficient diagnoses of air quality problems and has generated a comprehensive picture of local-level air pollution across the UK [17, 19]. Action Planning has, to date, been ineffective [17, 19], and interventions have been weak with few examples of sustained air quality improvements resulting from action plan measures with even fewer instances of AQMAs being revoked following implementation of an AQAP.

Air pollution remains a major problem in the UK and is undoubtedly a serious, intractable and long-standing problem directly linked to the growth in road traffic. It is a particular problem in the urban environments where high traffic flows, high emission rates and an exposed population in proximity to the emissions create the circumstance of a profound air pollution problem. In the UK, about 29,000 deaths per year are associated with exposure to fine particles, less than $2.5 \mathrm{~mm}$ in diameter $\left(\mathrm{PM}_{2.5}\right)$. This is about $6 \%$ of total deaths. In cities, $\mathrm{PM}_{2.5}$ primarily comes from diesel engine cars, heavy duty vehicles and buses but they are also produced by the burning of wood, heating oil or coal for domestic or industrial purposes.

The UK Committee on the Medical Effects of Air Pollutants (COMEAP) has estimated that the effects of $\mathrm{NO}_{2}$ on mortality are equivalent to 23,500 deaths annually in the UK [21]. Many of the sources of NOx ( $\mathrm{NO}_{2}$ and $\left.\mathrm{NO}\right)$ are also the sources of PM. The combined impact of these two pollutants is equivalent to more than 52,000 deaths per year and represents a significant public health challenge. Walton et al. [22] suggest that the mortality burden of $\mathrm{NO}_{2}$ and $\mathrm{PM}_{2.5}$ is such that some 9500 people die early each year in London due to long-term exposure to air pollution, this is more than twice as many as previously thought.

The World Health Organisation reports that in 2012 around 7 million people died - one in eight of total global deaths - as a result of air pollution exposure either indoors or outdoors [23 ]. Globally, 3.7 million deaths were attributable to ambient air pollution. This finding more than doubles the previous estimates and confirms that air pollution is now the 'world's largest single environmental health risk' [23]. These new data suggest that outdoor pollution from traffic fumes and coal-burning, and indoor pollution from wood and coal stoves, kills more people than smoking, road deaths and diabetes combined. Around $80 \%$ of the 3.7 million deaths from outdoor pollution came as a result of stroke and heart disease, $11 \%$ from lung diseases and 6\% from cancers. The vast majority were in Asia, with 180,000 in the Americas and Europe combined according to the WHO [23]. 
The WHO estimates the annual costs of air pollution to European economies is approximately US\$ 1.6 trillion in diseases and deaths [24]. For comparison, the total UK national debt in 2015 is about US\$ 2.55 trillion, whilst the Greek national debt is approximately US\$ 422 billion. The WHO cost estimates are derived from the amount societies are willing to pay to avoid these deaths and diseases with necessary interventions. In these calculations, a value is attached to each death and disease, independent of the age of the person, which varies according to the national economic context. The scale of the various estimates of health burdens and costs illustrates the size of the contemporary air pollution problem and are indicative of a situation where policy has failed to keep abreast of both the dynamic nature of scientific understanding and the scale of the problem. It may also be an example of where policy development and implementation has been retarded by the actions of vested interests. This is interesting to note in the light of the European Court of Justice who, in a Judgment of the Court (Second Chamber) on the 25th of July 2008,confirmed the enforceable 'right to clean air' for all EU citizens. The Court, in their interpretation of Article 7(3) of Council Directive 96/62/EC of 27 September 1996 on ambient air quality assessment and management, confirmed the entitlement of a third party whose health is impaired to have an action plan drawn up as provided for by the Directive, where that third party is entitled under national law to bring legal proceedings for measures to prevent the value limits of particulate matter being exceeded.

\section{THE NEW DEFRA AIR QUALITY PLAN}

In December 2015, Defra published its new Air Quality Plan 'Improving air quality in the UK. Tackling nitrogen dioxide in our towns and cities' [7]. This plan is the response of the UK to the decision of the Supreme Court to require the government draw up a plan for compliance by the end of 2015. The Plan presents a new assessment of the UK air quality position derived from modelling studies commissioned by Defra. The requirement for action set out in the Plan is much more modest than that previously identified by Defra. In 2013, the UK exceeded the EU limit value for $\mathrm{NO}_{2}$ annual mean at 31 of its 43 zones and agglomerations (38 excluding the Margin of Tolerance). In the new Plan, which acknowledges that full compliance will not be achieved until 2025, exceedences after 2020 are predicted only to occur in six locations, Birmingham, Leeds, Southampton, Nottingham Derby and London. In these locations, the government intends the Local Authorities to implement a new approach to pollution management through designation of a Clean Air Zone (CAZ). By 2020, the most polluting diesel vehicles - older buses, coaches, taxis and heavy goods vehicles - will be discouraged through a charging mechanism from entering the centres of Birmingham, Leeds, Southampton, Nottingham and Derby. It is intended that a CAZ will be tailored to the local circumstances so that in Birmingham and Leeds the restriction imposed will also target older diesel vans and in addition a range of other measures will be implemented to reduce vehicle movements including park and ride schemes, signage, changes in road layouts and provision of infrastructure for alternative fuels. London's strategy for improving air quality by 2025 includes the implementation of an ultra-low emission zone by 2020 , retro-fitting of buses and licensing new taxis to be zero emission capable from 2018.

The idea of a CAZ is, in principle, an intelligent response to the challenge of air pollution but it does appear that the government's intentions are quite limited and will not, for example seek to address the contribution of private cars to the air quality problem. Indeed the Plan does not appear to offer any new financial resources to implement the CAZ nor does it appear to be backed up by substantially new regulatory powers. Few of the measures outlined in the 
Plan can be described as novel and indeed most of the measures are already available to local authorities as part of their tool kit for air quality action planning.

In 2016, the House of Commons Environment, Food and Rural Affairs Committee published its report on Air Quality [25]. In this report, the influential Committee stated that deaths from air pollution represent a public health emergency for the UK. Furthermore, Defra's plans for CAZs to cut $\mathrm{NO}_{2}$ were criticised as giving local authorities insufficient control over implementation. The Committee noted that there are many more local authorities where EU limits are not met and for whom powers should be given to create a CAZ where local circumstances require one. In summary, the new Air Quality Plan suggests that progress towards compliance could be more rapid than previously projected, and that all UK zones could be compliant by 2025. However, the basis of the Air Quality Plan's conclusion that $\mathrm{NO}_{2}$ concentrations will be brought within EU limits by 2020 (2025 in London) is much more optimistic than the projections made previously. The basis of the projections appears to be a combination of model selection, input assumption and changes to vehicle emissions principally associated with the introduction of the new Real Driving Emissions (RDE) standard. Defra's plan to meet EU requirements by 2020 relies heavily on the newly agreed RDE standard to deliver substantially lower emissions but failure of the RDE standard to operate as intended will undoubtedly lead to more non-compliant zones in 2020 than currently predicted. The new Air Quality Plan simply does not go far enough to address the complexity and depth of air quality problems confronting many localities in the UK. Much more direct action is required to confront behaviours and vested interests that retard progress towards cleaner air for all.

\section{CONCLUSIONS}

Air quality in the UK and across the EU continues to pose a public health risk to much of the population. Efforts to control emissions and to manage and reduce exposure continue but are often under resourced, lack sufficient political support and public understanding and engagement is often absent. Ultimately air pollution is a choice society makes through its collective and individual behaviours and social practices. However, the consequences of those behaviours and choices will play out in many different ways with those who are least able to exercise choice having air pollution concentrations imposed upon them. History shows that concerted, collective and sustained action can lead to dramatic improvements in air quality. Society can choose to minimise the effects of air pollution. Do we want to change?

\section{REFERENCES}

[1] Brimblecombe, P. The Big Smoke, Routledge. 185pp, 1987.

[2] NSCA. Clearing the Air. 100 years of the National Society for Clean Air and Environmental Protection, NSCA: Brighton. pp. 22, 1998.

[3] Hansell, A., Ghosh, R.E., Blangiardo, M., Perkins, C., Vienneau, D., Goffe, K., Briggs, D. \& Gulliver, J. Historic air pollution exposure and long-term mortality risks in England and Wales: prospective longitudinal cohort study.Thorax, 2016. http://dx.doi.org/10.1136/thoraxjnl-2015-207111

[4] Sanderson, J.B. The National Smoke Abatement Society and the Clean Air Act 1956. Political Studies, 9 (3), pp. 236-253, 1961. http://dx.doi.org/10.1111/j.1467-9248.1961.tb00765.x

[5] Longhurst, J.W.S., Lindley, S.J., Conlan, D.E., Rayfield, D.J. \& Hewison, T. Air quality in historical perspective. Urban Air Pollution, eds H. Power \& N. Moussiopolis, CMP: Southampton, pp. 69-110, 1996. 
[6] NSCA. The Clean Air Revolution 1952-2052. Marking 50 years since the Great London Smog. National Society for Clean Air and Environmental Protection: Brighton, pp. 75, 2002.

[7] Defra. Improving air quality in the UK, Tackling nitrogen dioxide in our towns and cities, UK overview document, available at https://www.gov.uk/government/uploads/ system/uploads/attachment_data/file/486636/aq-plan-2015-overview-document.pdf, 2015.

[8] Defra. Local Air quality Management Policy Guidance (PG16), Department of Environment, Food and Rural Affairs: London, pp. 34, 2016.

[9] Department of the Environment. The United Kingdom National Air Quality Strategy, TSO: London, 1997.

[10] HM Government. Environment Act 1995 (Chapter 25, part IV). HMSO: London, 1995.

[11] Brunt, H., Barnes, J., Longhurst, J.W.S., Scally, G., \& Hayes E.T., Local air quality management policy and practice in the UK: the case for greater Public Health integration and engagement. Environmental Science and Policy, 58, pp. 52-60, 2016. http://dx.doi.org/10.1016/j.envsci.2016.01.009

[12] HM Government. Air Quality Regulations, 3043. HMSO: London, 1997.

[13] Department of the Environment, Transport and Regions, Scottish Executive, National Assembly for Wales, Department of Environment for Northern Ireland. The Air Quality Strategy for England, Scotland, Wales and Northern Ireland. CM 4548, TSO: London, 2000.

[14] Department for Environment, Food and Rural Affairs. The Air Quality Strategy for England, Scotland, Wales and Northern Ireland, Defra: London, 2007.

[15] HM Government. Air Quality Standards Regulations, HMSO: London, 2010.

[16] Barnes J.H., Hayes E.T., Chatterton T.J., \& Longhurst J.W.S., Air quality action planning: why do barriers to remediation in local air quality management remain? Journal of Environmental Planning and Management, 57(5), pp. 660-681, 2014. http://dx.doi.org/10.1080/09640568.2012.762573

[17] Longhurst, J.W.S., Irwin, J.G., Chatterton, T.J, Hayes, E.T. Leksmono, N.S., \& Symons, J.K., The development of effects-based air quality management regimes. Atmospheric Environment, 43, pp. 64-78, 2009. http://dx.doi.org/10.1016/j.atmosenv.2008.09.050

[18] EEA. Air Quality in Europe - 2015 Report. European Environment Agency report 5/2015: Copenhagen, pp. 57, 2016.

[19] Longhurst, J.W.S., Beattie, C.I., Chatterton, T., Hayes, E.T., Leksmono, N.S., \& Woodfield, N.K., Local air quality management as a risk management process: assessing, managing and remediating risk of exceeding an air quality objective in Great Britain. Environment International, 32, pp. 934-947, 2006.

http://dx.doi.org/10.1016/j.envint.2006.06.006

[20] Beattie C.I., Longhurst J.W.S, \& Woodfield N.K., Air quality management: evolution of policy and practice in the UK as exemplified by the experience of English local government. Atmospheric Environment, 35, pp. 1479-1490, 2001. http://dx.doi.org/10.1016/S1352-2310(00)00311-3

[21] Committee on Medical Effects of Air Pollution. Statement on the evidence for the effects of nitrogen dioxide on health, available at https://www.gov.uk/government/uploads/system/uploads/attachment_data/file/411756/COMEAP_The_evidence_for_the_ effects_of_nitrogen_dioxide.pdf, 2015. 
[22] Walton, H., Dajnak, D., Beevers, S., Williams, M., Watkiss, P. \&. Hunt, A. Understanding the Health Impacts of Air Pollution in London. Report for Transport for London and the Greater London Authority, available at https://www.london.gov.uk/sites/default/ files/hiainlondon_kingsreport_14072015_final.pdf, 2015

[23] World Health Organization. Burden of Disease from Household Air Pollution for 2012 Summary of Results, WHO: Copenhagen, 2014, available at http://www.who.int/phe/ health_topics/outdoorair/databases/en/.[24] World Health Organization. Economic Cost of the Health Impact of Air Pollution in Europe: Clean Air, Health and Wealth, WHO: Copenhagen, 2015.

[24] House of Commons. Air Quality. Fourth Report of Session 2015-16. Environment, Food and Rural Affairs Committee. Report HC 479, HoC: London, pp. 40, 2016. 